\title{
La administración de justicia indígena en Ecuador, un enfoque desde su cosmovisión
}

Fecha de recepción : 25 de diciembre de 2019 • Fecha de aceptación: 26 de marzo de 2020 • Fecha de publicación: 10 de mayo de 2020

\author{
Belkys Alida García ${ }^{1}$ \\ Universidad Metropolitana del Ecuador (UMET) \\ bealig-@hotmail.com \\ https://orcid.org/0000-0002-1509-5482
}

\section{Resumen}

Este artículo tuvo como objetivo un análisis crítico sobre la administración de justicia indígena en Ecuador, desde la cosmovisión indígena. En otras palabras, interpretar cómo la esta se deriva de las costumbres, mitos y leyendas provenientes de todo un aprendizaje de sus ancestros. Por otro lado, busca contrastar cómo y cuáles son los principales problemas que se presentan entre la justicia indígena y la ordinaria. Sus penas y/o castigos, cosmogónicamente, el elemento justicia no puede ser otra cosa que el reflejo de todos estos usos y costumbres. Gracias a las enseñanzas de adultos mayores, padres y abuelos, se fue formando un paradigma de respeto de valores, principios éticos y armonía. La ley natural es ese conjunto de normas objetivas que rigen la naturaleza, independiente de la voluntad del hombre; como es la ley del día, de la lluvia, del viento, el ciclo de la vida: nacer, crecer, reproducir y volver dándose de esta forma una relación del hombre y la naturaleza, conservando el equilibrio natural. El presente trabajo aborda un ejemplo de problemática de la aplicación de justicia por parte de los pueblos indígenas ecuatorianos: non bis in ídem, que en español significa "no dos veces por lo mismo", y que también es usada la forma ne bis in ídem.

Palabras clave: cosmovisión, justicia indígena, justicia ordinaria, non bis in ídem, ne bis in ídem. 


\begin{abstract}
This article aimed at a critical analysis about the administration of indigenous justice in Ecuador, from the worldview. In other words, interpret how indigenous justice derives from customs, myths and legends from a whole learning of their ancestors. On the other hand, contrast how and what are the main problems that arise between indigenous justice and ordinary. Their penalties and / or punishments, cosmogonic ally, the justice element cannot be anything other than the reflection of all these uses and customs. Thanks to the teachings of older adults, their parents and grandparents, a paradigm of respect for values, ethical principles and harmony was formed. Natural law is that set of objective norms that govern nature, independent of man's will; such as the law of the day, the law of rain, the law of wind, the cycle of life: to be born, grow, reproduce and return, thus giving a relationship of man and nature while preserving the natural balance. An example of the problem of the application of justice by Ecuadorian indigenous peoples is that of non bis in idem, which in Spanish means "not twice for the same ', and that the form ne bis in idem is also used.
\end{abstract}

Keywords: worldview, indigenous justice, ordinary justice, non bis in idem, ne bis in idem. 


\section{Introducción}

"Hay algo en la esencia de los pueblos que resulta persistente: lo cósmico y lo terrígeno. El negro, el indígena, el hombre antiguo encarnan conceptos que no coinciden con la mentalidad occidental, pero eso no puede dar pábulo para descartar herencias que pertenecen a la composición natural de nuestras raíces".

René Cortez, Rebetez

Al referirnos a la cosmovisión no podemos obviar una serie de planteamientos vinculados con la interculturalidad, como interrelación de saberes de las culturas originarias, con las culturas universales. Muchos de los saberes científicos de los pueblos originarios, indígenas, se están rescatando. Por ejemplo, cuando se habla de la medicina natural, las estructuras decimales de la matemática, las binarias, costumbres, clasificaciones de plantas, animales, de seres bióticos y abióticos, descubren un pensamiento de cosmovisión que en sí mismos poseen una ajustada racionalidad (Hevia, Oswaldo, 2017).

Conocido es que esa cosmovisión actual de los pueblos indígenas deviene en primer término de todo un proceso de transmisión oral de mitos y leyendas, así las historias de padres a hijos habían sido trasmitidas por los abuelos, a quienes no conocimos, pero según contaron sus antepasados, hace muchos años vino mucha gente mala de otros países y habían robado todas sus riquezas, desterrando a sus abuelos y bisabuelos de sus territorios y matando a mucha gente, por lo que las almas de sus antepasados, según ellos, pedían aún por la tierra y en las noches oscuras las "almas en pena" suplicaban por todos ellos y por la defensa de lo suyo.

Otros saberes y conocimientos fueron traídos de los pueblos indígenas más desarrollados, tales como los Incas, que llegaron hasta estas tierras desde el sur de Abya Yala, y de ahí el gran parecido con varios pueblos hermanos y por ende de la influencia cultural que actualmente se conoce proviene de otros países vecinos como Ecuador y Perú, en el caso de Colombia (Guerrero, 2003-2011).

En Ecuador, como ejemplo de mitos sobre su economía, se tiene el de los "shuar", basado en la agricultura, como casi todas las comunidades indígenas. Los "shuar" (Ilamados también "Jíbaros", término que consideran despectivo), son el pueblo indígena amazónico más numeroso (aproximadamente 80 mil individuos), habitan entre las selvas de Perú y el Ecuador, su Idioma es el shuar, se habla en la zona suroriental del Ecuador, donde se asientan comunidades indígenas shuar y está muy cercanamente emparentado con el huambisa del Perú. De ellos podemos relatar el célebre mito del "Nunkui y la yuca", el cual se refiere a que llegado un tiempo los "shuar" habían acabado todos los recursos de las llanuras que habitaban, un día "Nunku" (considerada Madre Tierra), le ofreció al pueblo a su hija como regalo, les advirtió que si cuidaban de ella les proveería de alimentos de toda clase, pero que si la llegaban a maltratar, sufrirían de nuevo por comida.

La comunidad aceptó y pudieron encontrar una cantidad de alimentos a su disposición, un día los niños de la comunidad lastimaron a la niña y, en castigo, la tierra se tragó los alimentos. Es 
por esto que hoy, elementos como la yuca, tienen que ser escudriñados bajo de la tierra (Cajal, Alberto. s/f).

Una leyenda ecuatoriana, que da fuerza a la cosmovisión de lo que era para los indígenas su territorio, pero también su libertad, es denominada “La leyenda de Guayas y Quil”. Dicho cuento se traslada a la época de la conquista de esa región, trata sobre el sacrificio de amor y libertad de la pareja de nativos guerreros de la tribu "huancavilca" al verse amenazado su territorio por parte de los españoles.

Se cuenta que, Sebastián de Benalcázar, conquistador español, fue el fundador de las ciudades ecuatorianas de San Francisco de Quito (1534) y Santiago de Guayaquil (1535), este tuvo muchos enfrentamientos fuertes con los indígenas de esas regiones para intentar establecer la nueva ciudad de Santiago. El cacique "Guayas" y su esposa "Quip" liderizaban las fuerzas nativas de resistencia, y eran admirables guerreros.

Casualmente, “Guayas” " "Quil” fueron capturados, "Guayas”, conocedor de la avaricia de sus invasores captores, ofreció a los españoles muchos tesoros ocultos a cambio de su libertad y la de su esposa. Así fue como los llevaron entonces hacia el "Cerro Verde" (actual cerro "Santa Ana"), fue allí cuando "Guayas" pidió un cuchillo para mover una de las piedras que cubría el acceso del escondrijo de los tesoros, pero en lugar de oro y piedras preciosas, "Guayas" hundió el cuchillo en el corazón de "Quil"y luego en el de él; prefirieron morir, a ser sometidos. La leyenda narra que este suceso aconteció cerca del actual río "Guayas", en donde se dice que cayeron los cuerpos de la pareja de indígenas. Es así como se relata territorialmente, uno de los orígenes de la ciudad de Guayaquil.

En ese sentido la existencia de los principios morales y éticos de los pueblos o comunidades indígenas. Los originarios de América Latina, sus indígenas, establecen que fueron educados por sus padres y abuelos con sus saberes. Sus principios se produjeron, según ellos, como resultado de las valiosas enseñanzas que recibieron. De la tradición oral, emprendida por los antepasados, aprendieron reglas de conducta social y ética que hoy en día se entiende fueron definitivas en la vida comunitaria de estas poblaciones, también aprendieron además pautas de armonía y convivencia para percibirse mejor entre ellos mismos y con los de afuera.

Indudablemente el elemento justicia no puede ser otra cosa que el reflejo de todos estos usos y costumbres, gracias a las enseñanzas de adultos mayores, sus padres y abuelos, se fue formando un paradigma de respeto de valores, principios éticos y de armonía con el cosmos. La ley natural es ese conjunto de normas objetivas que rigen la naturaleza, independiente de la voluntad del hombre; como es la ley del día, lluvia, viento, el ciclo de la vida: nacer, crecer, reproducir y volver dándose de esta forma una relación del hombre y la naturaleza conservando el equilibrio natural. Estas son las bases de conservar la justicia propia de los pueblos indígenas (Guerrero, 2012).

Los usos y costumbres de sus antepasados, trasmitidos oralmente de generación en generación, también fueron sus constituciones y las "curas" (entendido como castigo en nuestro paradigma de justicia occidental) dadas por sus mayores, se constituyeron en el reingreso al cosmos, a su purificación. Eso es lo que denominaron como su "Derecho mayor". Sus bases se asentaron sobre 
ellos mismos y no sobre instituciones inmóviles.

La justicia indígena comienza a ser visualizada, aunque ha existido ancestralmente desde hace muchos años. El profesor de la Universidad del Cauca, Herinaldy Gómez Valencia (2018), identifica varias concepciones acerca de la idea de la justicia o la idea de lo justo en las comunidades indígenas, estas pueden sintetizarse en: 1. La relación entre la cosmovisión y el territorio con las formas de control social y las prácticas de justicia. 2. La aceptación del conflicto como algo natural y su interés en prevenirlo y tratarlo preferentemente de manera amigable, en vez de acudir a medidas represivas y punitivas. 3. Concepciones singulares del consejo, como práctica para sanar y resarcir las ofensas. 4. El perdón como prevención de la venganza o la violencia, como forma de trascender la culpa y como una política de la amistad. 5 . El fortalecimiento de la justicia étnica mediante un proceso que conjuga la persistencia de concepciones ancestrales y la apropiación y resignificación de normas jurídicas estatales. 6. La compensación material del daño o la ofensa causados como medio de redistribución de bienes y a la vez como fortalecimiento o restablecimiento de alianzas sociales.

\section{Cosmovisión y justicia indígena}

La cosmovisión indígena invita a señalar enfáticamente que, por ejemplo, la cultura, matemáticas, lo geométrico, está en todas partes, lugares, normas y lenguajes, en otras palabras, en la cosmovisión de las comunidades indígenas desde tiempos pretéritos de la humanidad. Sustento de esta afirmación es que desde las primeras civilizaciones el hombre tuvo las incipientes aproximaciones interpretativas de lo que a sus ojos asombrados les ofrecía la naturaleza y el firmamento que veían allá, arriba en el cielo.

Por otro lado, es un hecho histórico singular que a nivel latinoamericano y en general suramericano, se ha tratado la temática y al mismo tiempo problemática de lo que debe ser una adecuada, legítima, justa y honesta aplicación de la justicia a los pueblos indígenas, ello no deja a un lado a la República del Ecuador. Primero, porque este país es uno donde existe una mayor representatividad de multiplicidad cultural que obliga a reflexionar acerca de la diversidad evidente, y segundo, porque ya desde los años 90' han ocurrido transformaciones, reformas constitucionales de gran valor al respecto en los países andinos, por lo que, ya finalizando esa década, proceden al reconocimiento constitucional como consecuencia obvia de la diversidad que en sus Estados conforman sus habitantes y comunidades en cuanto a la cultura, lo que los lleva a avalar esa evidente pluralidad cultural y el derecho a algo tan valioso y trascendente como lo es en consecuencia la identidad cultural.

Y es que lograr la definición de lo que representa la justicia ha sido uno de los problemas más álgidos desde hace muchos años. Varios autores han intentado abordar el tema desde sus diferentes disciplinas, tratando de llegar a un concepto aceptable y de consenso. En concreto, el tema de la justicia en las comunidades indígenas se ha hecho aún más complejo desde el punto de vista dogmático, debido al sistema oral que ellos manejan. Pero, no es absurdo llegar a una aproximación desde su propia cosmogonía, desde su mundo, y desde sus usos y costumbres, que son esencialmente disímiles al modelo conceptual occidental, porque la justicia, desde esta 
valoración, es de orígenes platónicos ante el logro o alcance pleno de la felicidad, capaz de poder controlar el cosmos, es parte del dominio de los sentidos.

Así, socialmente, es análogo al movimiento armónico de los astros y planetas, en cuyos movimientos observan que se sostiene coordinadamente ese movimiento y que individualmente poseen una belleza y un orden que les mantiene en un coordinado movimiento, e individualmente es un orden y una belleza en las porciones del alma. Es esta una de las explicaciones de la cosmovisión de la justicia. El reconocimiento a los pueblos indígenas ha sido el resultado de cambios internacionales y de la afortunada valoración de la alteridad como instrumento de reconocimiento del otro, con sus diferencias.

Algo a resaltar es que para Ángel Oquendo (2004), los pueblos indígenas que eligen cohabitar dentro de una misma región o país deben demandar que se les respeten los principios de igualdad y desacuerdo. Estas comunidades gozarían tanto de los derechos que tienen los ciudadanos de un país como del derecho a la autodeterminación de sus pueblos, podrían integrarse a la sociedad que residen, sin sacrificar su identidad, sin compensación alguna, solo así quedarían en contextos inmejorables para favorecer espléndidamente a un país pluralista.

Lo anterior trajo consigo una serie de respuestas manifiestas en materia de justicia social, por ejemplo, el reconocimiento de los distintos pueblos indígenas y sus derechos, por lo que se oficializan sus idiomas, se protegen sus costumbres, vestimentas, y se hacen promociones acerca de sus propias culturas.

Algo que es necesario establecer es que la justicia indígena tiene como objetivo fundamental el reconocimiento de los pueblos nativos como esencia primigenia para la construcción de la unidad nacional, basada en el respeto y ejercicio de derechos políticos, culturales, económicos y espirituales de todos los ecuatorianos, con el objetivo de conservar la armonía la paz y el equilibrio, entre los miembros de la comunidad.

En ese orden de ideas, al hacer un recuento de orden cronológico, se ha podido constatar que Colombia (1991), luego en Perú (1993), Bolivia (1994) y específicamente, en Ecuador en 1998, con la Constitución Política de 1998, se establecen criterios fundamentales basados en principios de tolerancia y respeto, para así permitir reconocer las discrepancias o similitudes culturales, étnicas y sociales de los diferentes pueblos y/o comunidades indígenas, como una vía para robustecer la unificación dentro de la diversidad al mostrarse de acuerdo con el derecho individual y colectivo de las personas.

Por lo tanto, si de justicia indígena se trata, es deber ineludible del Estado, en este caso el ecuatoriano, reconocer que la justicia Indígena se inicia desde el momento histórico en que se emprende la disputa de los indígenas por el reconocimiento y afirmación del ejercicio de la praxis y costumbres asentadas en el derecho consuetudinario o derecho propio de esos pueblos o comunidades. Así entonces, estamos hablando de un derecho con jurisdicción especial

Debe dejarse claro que desde tiempos ancestrales la aplicación de la justicia indígena, no preexiste como efecto de una disposición de política parlamentaria originada en base 
a discernimientos técnicos o de validez, sino que brota de la afirmación de un derecho, cuyo facultativo es una entidad agrupada, colectiva concretada en el "pueblo indígena". Es el fruto de un pueblo o comunidad indígena que por mucho tiempo ha construido una forma propia de administrar justicia en respuesta a sus usanzas y costumbres, con características atávicas procedentes de sus antepasados remotos y que muchas de ellas están latentes en las nuevas generaciones inmediatas.

Ahora, siguiendo lo determinado por Barié, C. (2003), en cuanto al interés demostrado por una administración de justicia acorde con las necesidades de los pueblos indígenas en Latinoamérica, éste señala que ello se acrecentó y sigue considerándose de suma importancia debido a diversas causas del mundo globalizado actual:

El desarrollo de la legislación en materia indígena y los cambios políticos en el hemisferio, hicieron necesario repensar el tema y profundizar algunos aspectos. El aumento de la participación indígena en los espacios de gestión política, los procesos reconstituyentes, las reformas políticas, la proliferación de la legislación secundaria, la creciente influencia del derecho internacional y de las agencias internacionales, todos estos elementos han contribuido a una visibilidad mayor de la presencia indígena en América Latina. Las fuentes bibliográficas se han multiplicado, y también es más fácil tener acceso a ellas a través del Internet.

Por otro lado, situándonos desde ahora en lo que se refiere al Ecuador, cuando seguimos a Díaz Ocampo (2015), en cuanto a la jurisdicción del Derecho indígena, sostiene que:

Conforme a la Constitución del Ecuador, se establece una jurisdicción especial indígena, orientada a romper dos aspectos básicos en la relación Derecho, Estado e indígenas. Es romper el monismo jurídico para aceptar y reconocer el pluralismo jurídico, romper el imperialismo jurídico, de extender categorías, principios, reglas jurídicas obligatorias que han impuesto a lo largo de la historia a los pueblos indígenas. Indudablemente este reconocimiento está sujeto a un sinnúmero de interpretaciones respecto de lo que es una sociedad multicultural, donde impera el pluralismo jurídico.

Ecuador es uno de los países latinoamericanos en el que conviven múltiples culturas, cada una con formas distintas de entender y ejercer la justicia. La justicia Indígena comienza con la lucha de los indígenas por el reconocimiento del ejercicio de las prácticas y costumbres basadas en su derecho consuetudinario o Derecho Propio.

Dentro de nuestra legislación la justicia indígena ya es reconocida desde la Carta Política de 1998 donde se introduce una sección específica. Por otra parte, de conformidad con lo previsto en la Constitución vigente desde el 2008, en el Capítulo Cuarto, se reconoce a la justicia indígena como un organismo de carácter nacional que se halla al mismo nivel de la Función Judicial.

Pese a esto, en forma crítica, se ha determinado que en cuanto a los derechos humanos la justicia indígena forjada en la Constitución del Ecuador presenta conflictos de competencias entre esas dos variables jurídicas. Se observa que las potestades indígenas, al igual que los jueces 
ordinarios, están en el deber de facilitar las garantías pertinentes para el logro del respeto de los exiguos jurídicos instituidos (mínimos jurídicos), con la finalidad última de respeto y frenar como praxis que se quebrante el debido proceso penal, medio por el cual deben ser respetados los derechos y garantías que le competen a cualquier ciudadano que es centro de una investigación, juzgándose así su conducta. Por otro lado, se han podido determinar asuntos en los que algunas comunidades indígenas no cumplen lo prescrito en la Constitución, en ese sentido, en lo respectivo a la determinación de la verdad en que se utilizan procedimientos y reglamentos vulneran los derechos humanos. Sobre todo cuando se han establecido los mínimos jurídicos antes mencionados y que se refieren a las limitaciones que se deben tomar en cuenta al momento de resolver un conflicto, estas limitaciones son algunas garantías que son iguales para todos los seres humanos y que las autoridades indígenas no pueden omitirlas:

1. Derecho a la vida: toda persona tiene derecho a la vida, y a la seguridad de su persona.

2. Derecho al debido proceso: como en todo proceso las partes tienen derecho a defenderse, ya sea personalmente o a través de terceros. Además, se tiene que cumplir con todos los principios, normas y reglas, con equidad e imparcialidad.

3. Derecho a la no tortura, esclavitud, ni tratos crueles: toda sanción será vigilada para que no caiga dentro de esta prohibición.

4. Derecho a la no agresión física ni psicológica: nadie será objeto de ataques a su honra o a su reputación. Toda persona tiene derecho a la protección de la ley contra tales ataques.

Y, considerando que todos los mínimos jurídicos mencionados anteriormente deben estar en consonancia con lo establecido como Derechos Humanos y que en resumidas cuentas se definen como inseparables a la persona, irrevocables, inalienables, intransmisibles e irrenunciables, dentro de un marco universal e igualitario. Son treinta (30) los artículos que integran el texto de la Declaración de los Derechos Humanos, y en el número uno se estipula con diáfana claridad que "todos los seres humanos nacen libres e iguales en dignidad y derechos y, dotados como están de razón y conciencia, deben comportarse fraternalmente los unos con los otros”. Además, en la Declaración se ampara que nadie será sometido a torturas ni a tratos crueles, inhumanos o degradantes. Todo individuo tiene derecho a la vida, a la libertad, a la libertad de pensamiento, de conciencia y de religión, así como a la de opinión y de expresión.

Aun cuando lo establecido en las normativas internacionales que reconocen los derechos indígenas, tal es el instituido en el Convenio 169 de la OIT (Organización Internacional del Trabajo) sobre Pueblos Indígenas y Tribales en Países Independientes, que es un tratado internacional adoptado por la Conferencia Internacional del Trabajo en Ginebra, el 27 de junio de 1989, y que determina que los pueblos o comunidades indígenas, deberán atesorar sus costumbres e instituciones propias, "siempre que estas no sean incompatibles con los derechos fundamentales definidos por el sistema jurídico nacional ni con los derechos humanos internacionalmente reconocidos." 


\section{Confrontaciones entre la aplicación de la justicia indígena y las leyes ordinarias en}

\section{Ecuador}

Para Gómez Valencia (2011, p.1) existe confrontación judicial entre la aplicación de la justicia indígena y las leyes ordinarias, por lo que algunas investigaciones realizadas no lo hacen factible, así establece enfáticamente, que:

Estos trabajos dejan por fuera el análisis de las repercusiones y los efectos interlegales de poder diferenciados que producen en los pueblos indígenas las disposiciones jurídicas que no han dejado de regularlos, sustrayéndose a su entendimiento como procesos semióticos e impidiendo captar el amplio rango de interacciones que tienen lugar en las relaciones interlegales. Estas interacciones no se contemplan a pesar de que las organizaciones indígenas aluden a ellas, reiteradamente, como un asunto problemático: estas reacciones indican que las justicias indígenas no pueden entenderse por fuera de un marco relacional entre narrativas de justicia locales y retóricas jurídicas nacionales y globales.

Al respecto de lo antes citado (supra), el mismo autor aclara que:

Para el propósito de este texto uso la acepción de "relaciones interlegales" como el campo en el que se agudiza y resalta la diferencia entre lo cultural y lo legal cuando ante la solución de un conflicto se genera una pugna interpretativa entre normas jurídicas estatales y normas culturales orales indígenas; pugna en la que éstas últimas acuden a formas de producción y movilización activa, creativa y deliberada de exaltación de diferencias culturales que por su condición de subordinación legal estatal terminan, generalmente, siendo desconocidas por la del derecho escrito, salvo que el conflicto se transforme y requiera una solución política que obligue a modificar la ley.

Un ejemplo de confrontación entre la aplicación de la justicia indígena y la ordinaria es que la justicia indígena ha aplicado castigos (penas) a algún (os) miembro (s) de su comunidad y resulta que posteriormente se intenta o se ha aplicado una pena o castigo judicial por medio de las leyes ordinarias, sea el caso de las leyes penales ordinarias del Ecuador, o viceversa. Ello por supuesto violenta el derecho, aquí se cumple la aplicación del término latín non bis in ídem, que en español significa "no dos veces por lo mismo", y que también es usada la forma ne bis in idem, y en otros idiomas autrefois acquitté ('ya absuelto' o 'ya saldado' en francés) y double jeopardy ('doble riesgo' en inglés), que es un principio general del derecho, y más concretamente un principio informador del derecho penal.

Por otro lado, algo indudable, si hablamos desde la perspectiva de la cosmovisión de los pueblos, es que los sistemas sancionatorios indígenas han ganado terreno en varios países, coexistiendo actualmente una dificultosa relación con la justicia oficial. Ellos se diferencian del Derecho Penal por cuanto parten de cosmovisiones diferentes, en los primeros, los pueblos indígenas, el centro de protección es la comunidad, a diferencia de los segundos en donde se prioriza al individuo. Esto judicialmente origina una separación en relación con ciertos principios reconocidos con la justicia oficial u ordinaria. 
Por lo tanto, el ámbito de aplicación del principio non bis in ídem permite alcanzar la importancia y preeminencia que tiene dentro del marco legal y constitucional garantizando la seguridad jurídica de los habitantes del Estado ecuatoriano, al no permitir la violación de sus derechos fundamentales, ya que excluye completamente la incertidumbre de la colectividad en su totalidad de volver a ser sometido a un nuevo juicio por un mismo delito y al cumplimiento de una sanción sea de naturaleza punitiva, pecuniaria, personal ( castigo físico o moral); en cuanto una persona que haya incurrido en el cometimiento de un hecho que se califica por la sociedad y la norma como un delito o contravención.

Por lo que, en el Derecho nacional e internacional se acentúa el respeto que debe tener la justicia indígena a los derechos humanos al momento de su aplicación y de igual manera establecen que los casos sentenciados mediante la aplicación de la justicia indígena deberán de ser respetados y acatados por todo funcionario del Estado. Este principio non bis in ídem tiene la capacidad especial de aplicabilidad en el ámbito de la extraterritorialidad ante la justicia estatal o justicia indígena, indicando que el mismo se administra imperativamente conservando el respeto a la soberanía de los Estados y reciprocidad entre los Estados que formen parte del conglomerado social.

Así pues, el Ecuador actualmente tiene reglas o normativas (Constitución del Estado Ecuatoriano, Ley Orgánica de Garantías Jurisdiccionales y Control Constitucional, Código Orgánico de la Función Judicial y Código Orgánico Integral Penal), que establecen y reglamentan la ejecución este principio non bis in ídem, las cuales hacen factible evitar el doble juzgamiento por el mismo hecho antijurídico en el que haya incurrido un ciudadano, de esta manera permitiendo que se mantengan y efectivicen las tradiciones, costumbres y cosmovisiones heredadas de sus ancestros a los integrantes o miembros de una comunidad, etnia, pueblo, tribus y/o nacionalidades.

Tanto en Ecuador como en Argentina, EEUU, Venezuela, Canadá, España, Perú, Colombia, República Dominicana, entre otros, es un derecho fundamental reconocido por sus Constituciones nacionales, que prohíbe que un acusado sea enjuiciado dos veces por un mismo delito, esto quiere decir que no pueda valorarse dos veces un mismo hecho o fenómeno para calificar el tipo de un delito o evaluar la concurrencia de circunstancias modificativas de la responsabilidad penal. Ante un tribunal un acusado además de declararse inocente o culpable puede manifestar que autrefois acquit (en francés ya he sido exculpado) si ya ha sido encontrado inocente en un juicio previo, así como autrefois convict (en francés ya he sido condenado) si el acusado ya fue enjuiciado y condenado.

Por supuesto, hay excepciones de la regla, en cuanto a la aplicación o no de la justicia indígena. Siguiendo a Sellan (2017), hubo un caso en donde no se aplicó la justicia indígena en Ecuador por una serie de condiciones que se exponen y describen a continuación. El caso fue el de "La Cocha", una comunidad indígena kichwa que tiene ocho mil habitantes aproximadamente, ubicada a 3400 metros sobre el nivel del mar, en la Cordillera de los Andes, región de la sierra central del Ecuador, provincia de Cotopaxi.

Esa comunidad vive de la agricultura (cebada, habas y papas) y de la ganadería, tiene escasos y deficientes servicios públicos, según así lo expresaban medios de comunicación. En la citada 
comunidad sucedieron dos hechos con notabilidad jurídica en los años 2002 y 2010, en el primero, el Cabildo hizo una junta con las trece comunidades del alrededor y avocaron conocimiento de un asesinato a un miembro de la comunidad decidiendo que la viuda recibiera dinero por el hecho de perder a su esposo (indemnización de seis mil dólares) y posteriormente en la plaza de La Cocha, con la presencia de casi 5000 indígenas, dos ciudadanos fueron declarados culpables del asesinato, ellos fueron castigados de acuerdo con la ley tradicional, lo que significa ser azotados trece veces y purificados con ortiga y agua helada.

Sin embargo, y para los efectos de esta investigación, nos referiremos al acontecido en el 2010. Conforme el acta de resolución realizada por las autoridades indígenas de la comunidad de "La Cocha", el domingo 9 de mayo de 2010 a las 19:00 aproximadamente, en el centro urbano de la parroquia Zumbahua, de población indígena kichwa hablante, cantón Pujili, provincia de Cotopaxi, se produjo el asesinato de Marco Antonio Olivo Palio. Las autoridades indígenas de las comunidades de "La Cocha" y Guantopolo conocieron el caso y establecieron la culpabilidad de cinco jóvenes indígenas e impusieron las sanciones conforme a la justicia indígena.

Esta decisión generó diversas reacciones en los medios de comunicación y en la sociedad ecuatoriana al punto de que el Fiscal General del Estado, pretendió ingresar arbitrariamente a la comunidad indígena, con el fin de rescatar a uno de los principales involucrados en la muerte. Los cinco responsables del asesinato se sometieron a la justicia indígena por su propia voluntad y aceptaron que se les aplique el sistema jurídico tradicional, pero, pese a esto, estaban siendo procesados y se encontraban en la cárcel número 4 de la ciudad de Quito, evidenciando así "un proceso de doble juzgamiento" (Caso La Cocha, 2014).

Así entonces, el 30 de julio de 2014, la Corte Constitucional del Ecuador resolvió el caso "La Cocha" y se decidió que la Asamblea General Comunitaria de pueblo kichwa panzaleo, cuando conoció el caso de muerte, no resolvió respecto de la protección del "bien jurídica vida" como fin en sí mismo, sino en función de los efectos sociales y culturales que esa muerte provocó en la comunidad, estableciendo diversos niveles de responsabilidad que son distribuidos, en distinto grado, entre los directamente responsables y sus respectivas familias, mientras que, por su lado, el ministerio público y la justicia penal ordinaria actuaron bajo la obligación constitucional y legal de investigar y juzgar la responsabilidad individual de los presuntos implicados en la muerte, por lo que esta Corte declara que no se ha configurado el non bis in ídem o doble juzgamiento. Más adelante, la Corte sostiene que conocer sobre los delitos que atentan contra la vida "es facultad exclusiva y excluyente del sistema de Derecho Penal Ordinario" aun si dichas infracciones se cometen dentro de las comunidades indígenas (Santamaría, el neoconstitucionalismo andino, 2016). Con lo dicho y a criterio de la Corte Constitucional del Ecuador, no se habría vulnerado el principio non bis in ídem en el caso "La Cocha" (justicia indígena), en virtud de que las comunidades no protegen el bien jurídico, sino que sancionan el impacto que el hecho genera en la comunidad tratando con de devolver la armonía a la comunidad.

Las reparaciones a las transgresiones a dichas normas pueden ser por la vía de la recomposición, la compensación, y/o la remediación de los daños causados, y no sólo por la vía del castigo, que es la forma preponderante en la Justicia Ordinaria u occidental.

A otros efectos, existen casos intermedios donde los indígenas han llegado a acuerdos con el 
Estado, como en Bolivia y Ecuador donde los indígenas pueden emplear como sanción la pena de cárcel en una prisión del Estado; o en Colombia, donde la justicia indígena pueda derivar casos al Estado, para que la justicia ordinaria realice el juicio, pero manteniendo a los indígenas su atributo de decidir cuál será la sanción.

El Estado no los reconoce constitucionalmente y pretende que ellos deben someterse a la legislación ordinaria por vía del establecimiento de sus órganos jurisdiccionales. No obstante, los indígenas toman esta decisión y acuden a las pretensiones de la justicia ordinaria, conociendo que sus decisiones no son válidas oficialmente, pero se niegan cuando la justicia oficial les criminaliza. Esta reacción se basa en usar sus propios métodos de resolución de conflictos y sus propias reglas al margen de Estado. Ello por supuesto crea una controversia entre la justicia ordinaria y la justicia indígena, con sus ulteriores consecuencias judiciales y jurídicas.

Algo a explicar es que el principio del equilibrio de las fuerzas de la comunidad es el más importante en las comunidades indígenas, por lo que se estaría ante sistemas de justicia "restaurativa", con el uso de técnicas de mediación, principalmente cuando se trata de justicia comunitaria. Se da el caso, por ejemplo, que en algunas entidades "kichwa"s del Ecuador, que la conducción comunitaria de los conflictos conducen al uso de la mediación comunitaria o la conciliación comunitaria, los objetivos de la pena o sanción son, por un lado, reponer el equilibro comunitario gestionando devolver la armonía rota, y de otro lado, devolver al individuo a la comunidad, para que comprenda que su acto ha incidido negativamente contra las fuerzas comunitarias, y de hecho, afecta también contra sí mismo.

Con respecto al significado que tiene la sentencisa para la comunidad indígena y para el sujeto mismo, en ocasiones las penas tienen un sentido más bien purificador. Ello se compadece en lo atinente a la aplicación de penas corporales como lo es el baño de agua fría y la ortiga que se ejecutan en el Chimborazo, Ecuador. El transgresor o abusador es castigado en presencia de toda la comunidad, a fin de que vislumbre que su hecho ha afectado el equilibrio de todos, con el agravante de que cada golpe, es corrientemente ejecutado por cierto familiar del penado $\mathrm{u}$ otro individuo que la comunidad registra con autoridad, ese castigo es acompañado con una exhortación o consejo, que permita corregir el daño, en este sentido es una pena correctiva.

Como ha sido mencionado, en la justicia indígena intervienen en primer lugar, la autoridad que frente al conflicto es un tercero interesado en restablecer la armonía en la colectividad, perturbada por el conflicto y no en satisfacer sus intereses propios, ni los de una parte solamente; en segundo lugar, la víctima de los actos $u$ omisiones que han infringido las reglas de la convivencia armoniosa o pacífica; y, tercero el responsable de los daños y omisiones dañosos (Trujillo, 2013, pág. 313).

Queda claro que la justicia indígena consiste en la purificación de un individuo cuando este comete actos contrarios a los principios de la Pachamama: el Ama Qhella, el Ama Llulla, el Ama Suwa (no ser ocioso, no mentir y no robar). De esta manera, hacer el ritual permite reintegrarse dentro de la comunidad.

En los juicios indígenas (el juzgamiento indígena), se pueden subrayar los siguientes momentos procesales: 
- Willachina (conocimiento del caso)

- Tapukuna (averiguación de los hechos)

- Chimbapurana (encontrar la verdad en la palabra de los responsables)

- Kishpichirina (determinación de las sanciones)

- Packtachina (cumplimiento de la sanción)

De esta manera, en cuanto a las sanciones y los tipos de conflictos en las comunidades se suscitan muchas acciones negativas que causan intranquilidad, enemistades entre las familias y mucha preocupación a la organización comunitaria, que conducen como resultado final a "la tristeza de las personas". Situaciones generadoras de llaki.

En referencia a los tipo de sanciones podemos mencionar que el primer es el consejo (amashina), se trata de una práctica acompaña al proceso de juzgamiento en sus diversas etapas y es el mecanismo más utilizado para la transmisión de prácticas y valores propias de la cultura Kichwa. El segundo está relacionado con la imposición de sanciones económicas, a más del valor propiamente económico de reposición de algún bien material perdido, robado o destruido, o algún daño físico a la persona. El tercer tipo de penalidad está determinado con la imposición de castigos físicos, se utiliza el azote con látigo de cuero ovino, el baño en agua fría, transporte de piedras en la espalda y la denominada "ortigada" o azotaina con ortiga. Otro castigo con fuerte carga moral es la expulsión física de la comunidad por un cierto tiempo o en forma definitiva, muchos hablan de una especie de "muerte social" (Serrano, 2012).

\section{Caso de violación de los derechos humanos de indígenas ecuatorianos por parte de extranjeros}

Aunque es un caso no directo de violación de los derechos humanos por parte del Ecuador, conviene expresar la posición o conducta de sus autoridades. Una evidencia de violación de derechos humanos y obviamente de los derechos indígenas de Ecuador lo constituyó el caso conocido por la extracción ilegal de sangre, a la que fueron sometidos indígenas ecuatorianos hace dos décadas. Este suceso involucra a una petrolera y un instituto médico de Estados Unidos, también se dio en otros países amazónicos. Se pudo determinar que en julio 2012, la Defensoría del Pueblo de Ecuador (DPE), denunció que el Instituto Coriell, un centro de investigación médica ubicado en Nueva Jersey (EEUU), comercializaba ilegalmente material genético de nativos huaorani de la Amazonia ecuatoriana. Este material genético había sido enviado por el Instituto Coriell a ocho países, en un caso que también involucra a la Universidad de Harvard.

Luego, sustentada en testimonios de huaorani, la DPE señaló que dos estadounidenses, entre ellos un médico de la petrolera Maxus (con sede en Texas, EEUU), tomaron a inicios de los años 1990 muestras de sangre a aborígenes alegando que serían utilizadas para exámenes cuyos resultados nunca fueron presentados a las autoridades ecuatorianas en materia de salud. 
Posteriormente, pudo comprobarse que el Instituto Coriell tiene en sus bases muestras y vende material genético de la nacionalidad huaorani. Estas muestras fueron adquiridas después por un científico de la Escuela de Medicina de Harvard, señaló hace dos años la DPE. Pudo conocerse, que la petrolera Maxus operó en la provincia amazónica de Orellana (este) hasta mediados de los 1990, y amplió su actividad a través de otra petrolera.

Esa jurisdicción concentra a la nacionalidad huaorani, integrada por unas 3.000 personas según estimaciones de organizaciones indígenas. De los huaorani, que se mantenían alejados de la civilización, sobreviven los clanes "taromenane" y "tagaerr", los dos únicos pueblos nómadas aún en aislamiento voluntario que se mueven en una amplia zona selvática.

En agosto de 1996 dos científicos brasileños denunciaron la venta ilegal a través de Internet, por parte de Coriell, de muestras de DNA (ácido desoxirribonucleico, portador de códigos genéticos) proveniente de indígenas karitania y suruí, que habitan el estado amazónico de Rondonia (limítrofe con Bolivia). En el caso ecuatoriano, Coriell admitió que repartió muestras de sangre tomadas a huaorani a varios institutos científicos del mundo.

En realidad, esta acción ilegal vulnera derechos humanos de la nacionalidad huaorani, sobre todo porque en ningún momento estos fueron informados sobre los fines que tenía la extracción de sangre, lo cual constituye un delito de engaño y fraude.

Se conoció por parte del ministro de Educación Superior y Ciencia de Ecuador, René Ramírez, que entre los huaorani hubo unos 3.500 procedimientos de extracción de sangre, lo que significa que se tomaron algunas pintas (450 mililitros) de sangre a una persona más de una vez. Según el presidente de Ecuador de esa época, Rafael Correa, el plasma fue sometido a "experimentos" debido a que los aborígenes amazónicos son "inmunes a ciertas enfermedades". Lo que sí está jurídica y constitucionalmente claro es que la Constitución Nacional de Ecuador prohíbe el uso de material genético y la experimentación científica que atente contra los derechos humanos.

La conducta y posición de la justicia ecuatoriana se redujo o estuvo centrada en solamente lo denunciado por la defensoría del pueblo, como ya ha sido conocido. Las autoridades de Quito acusan a tres entidades de Estados Unidos de haber actuado con fines comerciales al sacarle sangre a miembros de la comunidad huaorani, con unas 3.000 personas actualmente y que hace décadas vivía en aislamiento voluntario en la Amazonia ecuatoriana.

En la actualidad está en vigor el Código Orgánico de la Economía Social de los Conocimientos, la Creatividad y la Innovación. Del mismo modo, el Código Orgánico Integral Penal regula la biopiratería en su artículo 248 al establecer los delitos contra los recursos del patrimonio genético nacional y sanciones con penas de privación de libertad entre 3 y 5 años. Con esto, se evita que se repitan casos como el de la toma ilegal de muestras de sangre a los pueblos ancestrales ecuatorianos.

A esta regulación penal se suma el Código Orgánico de la Economía Social de los Conocimientos, la Creatividad y la Innovación de 2016 que incluye un capítulo específico sobre el tema de saberes tradicionales e investigación responsable. 


\section{Conclusiones}

En primer término, la justicia y la legislación ecuatoriana protege a todo el colectivo social a nivel nacional otorgándole la facultad de acceder y estar protegido por la ley estatal y difundir en áreas públicas sus expresiones ancestrales y culturales, intercambiando sus creencias y practicas ancestrales sin limitación alguna de aplicar su justicia.

Al situarnos en la cosmovisión de los pueblos indígenas ecuatorianos, hemos de expresar como aspectos de la interculturalidad, que la misma tiene un carácter imperativo de aplicación, esto es que no tenemos la facultad de usarla sino la obligación de hacerla efectiva, y cómo, pues en el diario vivir reconociendo que vivimos al mismo tiempo en un Estado unitario pero lleno de diferentes culturas de igual valor a la hegemónica (población blanco-mestiza).

La dirigencia de los pueblos, comunidades, etnias y nacionalidades indígenas son legítimamente elegidas por sus miembros, que normalizan diversos ámbitos de las actividades sociales y solución de todo tipo de conflictos que se causen dentro de la misma, para así mantener el equilibrio ante un conflicto jurídico entre las autoridades judiciales ordinarias y las autoridades indígenas quienes buscan medidas equitativas para restablecer y regular la convivencia de la sociedad que representa en fin la víctima, el colectivo, por medio de un desagravio o resarcimiento del daño causado, se aplican castigos correctivos y ejemplarizantes para el resto de miembros de la comunidad, etnias, pueblos o nacionalidades.

Pueden presentarse confrontaciones de tipo judicial o jurídica en la aplicación de las penas o castigos que sean considerados por la justicia indígena o la justicia ordinaria. Pero, en esos casos existen soluciones a nivel internacional y local que permiten interpretar cuando existe excepción o no, sea el caso por ejemplo de aplicación del ne bis in idem o el nom bis idem.

Cosmogónicamente, en cuanto a la justicia indígena, se ha de afirmar que el principio independiente que los indígenas dan a sus justicias, denominándolas sea como "ley de origen", "derecho propio," o "leyes de la madre tierra") puede conservarse y avanzar si se les permite mantenerse en la oralidad, en lengua nativa o en español y si siguen siendo derivadas e impartidas por la comunidad. Si se cambia a escritura de alguna manera disipará su autonomía porque será mediada por la justicia ordinaria con el carácter del derecho escrito, es decir, desde la distancia de la esencia y carácter restructurador de la ley. Sabemos que las justicias indígenas y sus lenguas son, fundamentalmente orales, pero poco sabemos sobre "qué dicen, cómo lo dicen y por qué dicen lo que dicen". En ese sentido, debería mostrarse a través de la lingüística a los expertos y de descifrar sus gramáticas y sus sentidos de justicia. 


\section{Referencias bibliográficas}

Barié, C. (2003) Pueblos Indígenas y derechos constitucionales en América Latina: un panorama. Editorial Abya Yala. La Paz.

Cajal, A. (s/f). Las 10 Leyendas y Mitos Ecuatorianos Más Conocidas (Cortas). Cultura General. Lifefeder.com. [https://www.lifeder.com/leyendas-ecuatorianas/]

Convenio 169 y la declaración de los derechos de los pueblos indígenas de la ONU (2007).

Díaz Ocampo, E. (2015). La formación en la justicia indígena como alternativa frente al pluralismo jurídico. Universidad Técnica Estatal de Quevedo, Ecuador.

Gómez Valencia, H. (2011, p.470). Justicias orales indígenas y sus tensiones con la ley escrita. Jornadas sobre Justicia y diversidad en América Latina. Pueblos indígenas ante la globalización. Victoria Chenaut, Magdalena Gómez, Héctor Ortiz y María Teresa Sierra (coordinadores). https://www.flacsoandes.edu.ec/

Gómez Valencia, H. (2018). Revista de Ciencias Sociales "De la justicia y el poder indígena". Convergencia., vol. 8, núm. 25, mayo-agosto.

Guerrero, J. A. (2003-2011). Continente Americano. Pueblos indígenas de Nariño.

Hevia Araujo, O. (2017). Lingüística matemática, Etno-matemática y su incidencia sobre el lenguaje intercultural bilingüe de los indígenas (Educación Primaria Latinoamericana).

Ponencia en Tercer Congreso Anual de Estudios Hispánicos: Lenguas, Escrituras, y Cultura en la nueva Arena política. Universidad de Houston, Texas, EEUU.

ONU (2007) Declaración de las Naciones Unidas sobre los pueblos Indígenas.

Oquendo, A. R. (2004). Democracia y pluralismo. México D.F. Fontamara S. A.

Sellan Zambrano, W. (2017). El principio non bis in ídem, frente a la justicia indígena en ecuador. Trabajo de titulación presentada como requisito previo a optar por el Grado Académico de Magister en Derecho Constitucional. Diciembre del 2017. Universidad de Especialidades Espíritu Santo Facultad de Postgrado. Samborondón, Guayaquil, Ecuador.

Serrano, F. G. (2012). No se aloquen, no vayan a carrera de caballo, vayan a carrera de burro: comunidades de Chimborazo y Chibuleo. En B. d. Grijalva, Justicia indígena, plurinacionalidad e interculturalidad en Ecuador. (pp. 540-542). Abya Yala, Quito, Ecuador. 
Sentencia. (2014). Corte Constitucional del Ecuador resolvió el caso "La Cocha". Expediente N¹13-14- CCE. sep. -

Trujillo, J.C. (2013). Constitucionalismo contemporáneo. Corporación Editora Nacional y Universidad Andina Simón Bolívar, Quito, Sede Ecuador. 
Copyright (c) 2020 Belkis Alida García

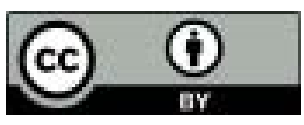

Este texto está protegido bajo una licencia internacional Creative Commons 4.0.

Usted es libre para Compartir-copiar y redistribuir el material en cualquier medio o formato - y Adaptar el documento - remezclar, transformar y crear a partir del material-para cualquier propósito, incluso para fines comerciales, siempre que cumpla las condiciones de Atribución. Usted debe dar crédito a la obra original de manera adecuada, proporcionar un enlace a la licencia, e indicar si se han realizado cambios. Puede hacerlo en cualquier forma razonable, pero no de forma tal que sugiera que tiene el apoyo del licenciante o lo recibe por el uso que hace de la obra.

$\underline{\text { Resumen de licencia - Texto completo de la licencia }}$ 